\title{
Meio Ambiente - Na Perspectiva do Criador e da Criatura
}

\author{
Marcos Bella Cruz Silva ${ }^{1}$ \\ Rosana Ravaglia ${ }^{2}$
}

Ensaio

Assay

cientistas e professores universitários em Oxford, estudiosos das ciências naturais, ambos mantêm uma relação de amizade apenas de cordialidade.

São abertos a novas formas de pensar, desde que as evidências os levem a isso. A diferença é que o raciocínio lógico levou Dawkins a pregar o ateísmo e Mc Grath a acolher a fé.

\section{GÊNESIS, 1,1}

\section{No princípio, Deus criou o céu e a} terra.

No início era apenas algo diminuto, milhares e milhares de vezes menor que a cabeça de um alfinete. A temperatura, fora de escala referencial para os dias de hoje; em conjunto as quatro interações energéticas básicas do universo: a gravitacional, a eletromagnética, as forças nucleares, forte e fraca, unidas, constituindo uma única força não particularizada.

$\begin{array}{rrrr}\text { Respaldado na } & \text { "certeza" } & \text { da } \\ \text { cosmogênese atual, e } & \text { embasado } & \text { no }\end{array}$ conhecimento dos ilustres especialistas, fica ainda o seguinte questionamento.

Quem verdadeiramente entornou o caldo? Há culpado(s)?

Como diz Leonardo Boffem seu livro, Ecologia Grito da Terra-Grito dos Pobres, "Nós somos como partes do universo, todos irmãos e irmãs: as partículas elementares, os quarks, as pedras, as lesmas, os animais, os humanos, as estrelas, as galáxias".

Portanto, somos todos coresponsáveis, pela (r)existência do homem, pelo piar dos pássaros, pelo barulho do vento, pelo parar do tempo.

Conforme Gênesis, Deus é a própria

${ }^{1}$ Especialista - Gestão Ambiental - Químico

${ }^{2}$ Doutora - Professora do Mestrado em Ensino de Ciências da Saúde e Meio Ambiente e Engenharias - UniFOA 
criação, "presente" no início da construção da casa, "oicos", ELE, arquiteto dos arquitetos, construiu A CASA em solo fértil sem contaminação ambiental e quimicamente equilibrado através de seus constituintes micro e macro elementares.

Dotada de infra - estrutura necessária ao bom funcionamento do ambiente, com vários quartos, espaço amplo, com direito a vaga na garagem, tráfego sem congestionamento água e alimento em abundância, tratamento de lixo e esgoto sanitário operando em patamares compatíveis com o bom senso esperado.

Enfim, aproveitamento inteligente em cores vivas. Pasmem porém senhores, tudo isto, sem a necessidade de uma consultoria aos planejadores e gestores de plantão ou prévio estudo de impacto ambiental.

Por motivo de viagem, fez um contrato de locação, baseado apenas nas alíneas do respeito, da solidariedade, da partilha, da generosidade e da confiança.

É possível que DEUS tivesse apenas sussurrado, e o homem sempre pouco disposto a ouvir, não tenha entendido que voltaria um dia para dar uma verificar o estado e as condições de seu "oicos".

Talvez também, por falta de atenção ou sensibilidade, é bem provável que o homem tenha entendido como vistoria geral da CASA, a necessidade de Sua presença física!

Homem moderno e ocupado, não sabe mais ler cartas ou receber mensagens subliminares, apenas "torpedos" e mensagens eletrônicas. O carteiro e os poetas do ambiente, há pelo menos quatro décadas, batem a porta sem, no entanto, lograr êxito na entrega do envelope ao destinatário.

Pobre homem, talvez perceba tardiamente as cobranças do SENHORIO, quanto aos itens contratuais, desenvolvido a base da confiança, da ética e do respeito.

Infelizmente, o relatório atual de auditorias, interna e externa, vem apresentando tópicos de não conformidade em vários itens. Com atenção especial àqueles embalados pela arrogância, pela insensatez e pela ganância.

Espera-se que o homem reflita e apresente urgentemente novos planos de ajustes de conduta. Baseados, principalmente em pontes que liguem aos caminhos da ternura, do cuidado, do AMOR MAIOR.

Caso contrário,...!

\section{GÊNESIS 1, 3}

Deus disse: “Que exista a luz!" E a luz começou a existir.

A luz pode ser compreendida como uma forma de energia. Esse fenômeno pode ser observado na fornalha solar que atinge milhares de graus. A superfície da terra é iluminada e aquecida pelo sol.

A luz é fundamental para os vegetais que a utilizam para a produção da fotossíntese. Processo onde a água, o gás carbônico, a clorofila e enzimas, na presença de energia luminosa, produzem material celular e oxigênio.

Os estudos que envolvem o caráter ondulatório da propagação da luz propiciaram o conhecimento e o desenvolvimento das técnicas que envolvem os espectros eletromagnéticos.

Em função de seu comprimento de onda, os espectros variam do infravermelho ao ultravioleta, passando pela região do visível, faixa onde a retina humana consegue enxergar.

Niels H. D. Bohr (1885 - 1962), físico teórico renomado recebeu o premio Nobel em 1922 por estudos nesta área. Especialmente pela criação do seu modelo para o átomo. Reconhecidamente um ortodoxo defensor da mecânica quântica, Bohr percebeu rapidamente que inovações tão perturbadoras iriam ocasionar mudanças de rumos nas áreas do conhecimento científico e tecnológico.

Com o aperfeiçoamento das novas ferramentas, aliados às necessidades industriais e de consumo, o homem passou a ter contato com um número cada vez maior de radiações: mostradores luminosos de relógios a base de fósforo, equipamentos que emitem radiações eletromagnéticas na faixa de altas freqüências (fornos de indução, transmissores de rádio, receptores de televisão, radares, telefonia celular, uso de radiações radiativas para uso médico e industrial entre outros.) e ,particularmente, a radiação nuclear, que além de ser muito perigosa e mortal (utilização em guerras) é potencialmente poluidora, em virtude dos resíduos radioativos.

Por esse motivo requer métodos especiais para sua disposição ou lançamento. O homem, hoje, sabe, através de amargas experiências, que o seu organismo tolera pequenas doses de radiações de alta energia.

Ressalta-se ainda, o fato dessa energia 
não ser detectada pelos sentidos, a não ser em doses maciças, sendo assim age de forma cumulativa no organismo. Desta maneira, em função de sua intensidade e energia podem ocasionar doenças como o câncer ou mutações genéticas.

Convém também ressaltar o chamado "efeito estufa" (incubadora). A expressão "efeito estufa" indica um fenômeno natural conhecido e é caracterizado pelo aumento de temperatura da atmosfera terrestre. O planeta Terra irradia para o espaço uma quantidade igual àquela absorvida do sol. Essa irradiação ocorre sob a forma de radiações eletromagnética na faixa de comprimentos de onda do infravermelho (IV).

Esta radiação fica retida na atmosfera em virtude da presença de alguns gases que absorvemgrandepartedelaeconseqüentemente aquece a atmosfera. A radiação é direcionada de volta a superfície, é reabsorvida e provoca aquecimento na superfície do planeta.

O aumento da concentração de alguns gases indutores do "efeito estufa" (dióxido de carbono - $\mathrm{CO} 2$, metano - $\mathrm{CH} 4$, óxido nitroso - N2O, clorofluocarbonetos - CFCs, hexafluoreto de enxofre - SF6) é responsável pelo aumento de temperatura do planeta. Concomitante a outros fatores estima-se um aumento de temperatura na faixa de $2^{\circ} \mathrm{C}$ a $6^{\circ} \mathrm{C}$ para os próximos cem anos. Esse aumento de temperatura seria maior do que qualquer outro ocorrido desde o aparecimento da civilização humana na terra.

\section{GÊNESIS 1,4}

\section{Deus viu que a luz era boa. $E$ Deus separou a luz das trevas. \\ O planeta e as futuras gerações} agradeceriam aos atuais "condôminos", a capacidade destes em nortear seu iluminado olhar na direção do norte, sem deixar, no entanto, um rastro indesejável, muito menos, perder o facho de luz da cena presente, baseado na responsabilidade, na generosidade e no equilíbrio.

Diante da atitude paternal e generosa do PAI, ao separar o joio do trigo, o movimento natural da espécie humana seria partilhar os conhecimentos adquiridos e desenvolvidos de forma a fundamentá-los no caminho do equilíbrio e da sustentabilidade, que segundo Juha Sipila, ambientalista finlandesa, significa: "Usarmos nossa ilimitada capacidade de pensar resguardando nossos limitados recursos naturais".

É bem verdade, que é impossível deixar de assinalar, que muitos "trigos de luz" ultrapassaram os meches da peneira, momento onde a inteligência humana esteve a serviço das vidas presentes e futuras. Exemplos na medicina, onde o avanço das técnicas radioativas e instrumental (ressonância magnética, lazer, quimioterapia, etc) são fundamentais para a cura de doenças, há cinqüenta anos atrás, inimagináveis.

Talvez o que esteja faltando ao ser humano seja a incorporação de um prisma interno com resolução sensível capaz de associar os caminhos sutis a trilhar na cadência dos passos a marchar. Quem sabe, esta seria uma maneira de separar a luz convergente da luz interferente, a claridade da escuridão, a luz das trevas!

O homem não se deu conta que a não separação dos ruídos interferentes, contribui sobremaneira para a morte do planeta. Desta forma impossibilitando vida qualitativa aos seus pretéritos futuros semelhantes.

Geralmente, algumas dessas atitudes são tomadas visando sempre o bem estar de uma pequena minoria, pertencentes a uma sociedade do ter, do ostentar e do consumo desenfreado.

Entretanto, a trajetória da humanidade tem sido pontuada, também, através de exemplos daqueles que foram e ainda o são, luz para existência e para a trajetória de vida igualitária de seus semelhantes.

O clarão da vaidade, da insensibilidade, da promoção interessada ou da temível picada da "Mosca Azul" não foram empecilhos para uma eterna visão.

Dentro desta rede de pensamentos e atitudes, a começar pelo FILHO da própria luz inicial de Gênesis, podem ser citados também, alguns contemporâneos, tais como, Martin Luther King, Madre Tereza de Calcutá, Mahatma Ghandi, Chico Mendes, José Lutzemberg, Irmã Dorothy Mae Stang e tantos outros anônimos.

Enfatizamos, porém, um exemplo recente do nosso cotidiano, a quase despercebida atitude tomada por Frei Betto, oriundo das lutas dos Dominicanos na busca da caridade, da fraternidade e ética. Seus ideais de igualdade e liberdade transcenderam a tranqüilidade e a calmaria dos conventos ao 
alcançar os embates urbanos.

Convidado e nomeado, pelo governo atual, na mobilização social do programa "Fome Zero", deixou o cargo dois anos depois, talvez por acreditar, como no poema de José Régio:

"Não sei onde vou,

Não sei para onde vou,

Sei que não vou por aí.

Não vou pelas vias que conduzem os passos do inimigo.

Não trilharei os caminhos sombrios, tortuosos da corrupção, da sonegação, da falcatrua e da negociata."

Ou ainda conforme declara o poeta Mario Quintana:

"Enquanto uns saem para caçar borboletas, prefiro cuidar do jardim para que elas venham".

Exemplos que dignificam a crença no amanhã e na esperança. A verdadeira vitória da luz às trevas.

\section{GÊNESIS 1,6}

Deus disse: "Que exista um firmamento no meio das águas para separar águas de águas!"

Dentre os principais poluentes atmosféricos encontram-se os materiais particulados, tais como os aerossóis, condições em que se encontram os clorofluorcarbonos (CFCs).

Quando emitidos para atmosfera as cinzas, material do tipo sólidos finos, normalmente provenientes da queima de combustíveis e a poeira, partículas sólidas, são capazes de permanecer temporariamente suspensas no ar.

Os gases e vapores gerados e emitidos pelas indústrias contêm compostos de enxofre, de nitrogênio, de carbono, orgânicos (hidrocarbonetos, aldeídos e ácidos orgânicos), os halogênios e seus derivados, os oxidantes e os metais pesados.

O comportamento do ozônio (O3) na atmosfera deve ser um motivo para reflexão. Através de um processo natural é formado nas grandes altitudes pela ação dos raios ultravioletas sobre o oxigênio atmosférico. A camada de ozônio formada na estratosfera (cerca de $35.000 \mathrm{~m}$ de altitude) tem como função primordial absorver radiação ultravioleta emitidas pelo sol.
Entretanto, nos grandes centros urbanos, a vertente oxidante da camada de ozônio está presente de maneira prejudicial. O O3 é formado através de reações fotoquímicas, principalmente dos óxidos de nitrogênio (NO, $\mathrm{NO} 2$ ), e são provenientes das emissões de veículos automotores.

Os gases oxidantes, quando próximos à superfície da terra, são nocivos à saúde humana. Os sintomas mais observados da intoxicação através da poluição atmosférica são a metahemoglobinemia (cianose) e edemas pulmonares.

Quanto aos malefícios causados aos vegetais estão principalmente a diminuição da permeabilidade das membranas celulares e a queda da capacidade fotossintética das plantas, em virtude da destruição da clorofila.

Os contaminantes radioativos são outros poluentes atmosféricos a serem considerados. Muito embora alguns elementos químicos emitem tais radiações para atmosfera de maneira natural.

A partir da segunda guerra mundial, com os estudos adiantados sobre o núcleo do átomo, está espécie de radiação continua até os dias atuais, sendo alvo de preocupações por parte da humanidade.

Os problemas causados por estas emissões estão associados à meia vida biológica dos isótopos radioativos. Logo, quanto maior a meia vida biológica de um isótopo radioativo, maior será o comprometimento do órgão humano afetado.

\section{GÊNESIS 1,7}

Deus fez o firmamento para separar as águas que estão acima do firmamento das águas que estão abaixo do firmamento. E assim se fez.

No Planeta Terra, dois terços da superfície, ou $71 \%$, são cobertos por água. De toda a água existente na Terra, apenas $2,5 \%$ são doce, sendo que $70 \%$ estão nas geleiras polares assim restando $0,75 \%$ para dividir entre os seis bilhões de humanos. Estes $0,75 \%$ de água é classificado como superficial e subterrânea. Esta última encontra-se armazenada no subsolo, em rochas chamadas de aqüíferos, perfazendo $97 \%$ de toda a água disponível, em condições de ser explorada, física e economicamente, pelo homem. As águas superficiais estão distribuídas em bacias hidrográficas (rios, lagos, etc) e representam 
apenas 3\% das reservas de água doce.

Hoje, sabemos que a água é um recurso limitado e de valor econômico. Sua escassez pode ocorrer, tanto por condições climáticas e hidrogeológicas, como por demanda excessiva.

Nada é mais abundante do que a água. Por isso, é difícil imaginar que sua escassez possa causar mortes, conflitos internacionais, ameaças a sobrevivência de animais e plantas e comprometer alguns setores da economia.

Entretanto, tal cenário é cada vez mais recorrente. Apenas um quarto da humanidade terá água para as suas necessidades mínimas em 2025. A estimativa é da Organização das nações Unidas (ONU), que considera os recursos hídricos uma de suas preocupações prioritárias. Além disso, no último meio século, a disponibilidade de água por ser humano diminuiu $60 \%$, enquanto que a população aumentou $50 \%$.

Em algumas partes do planeta, a crise já começou. Nos quarenta países mais secos, a maioria deles na Ásia e na África, um cidadão tem direito a, no máximo, oito litros de água por dia. Pelos cálculos da ONU, um indivíduo adulto precisa de algo em torno de 50 litros diários para viver, ou seja, para ingestão, preparo de alimentos, diluição de esgotos e higiene pessoal. O cálculo não inclui dezenas de milhares de litros gastos na agricultura, na pecuária ou na indústria. Atualmente $70 \%$ da água doce disponível no planeta é utilizado na agricultura. Segundo o Conselho Mundial de Ägua (World Water Council), no ano 2025 serão necessários mais $17 \%$ desse recurso para alimentar o mundo.

Poluição é a contaminação da água com substâncias que interferem na saúde das pessoas e animais, na qualidade de vida e no funcionamento dos ecossistemas. Alguns tipos de poluição têm causas naturais, tais como, erupções vulcânicas. Porém a maioria é causada pelas atividades humanas. Com a crescente sofisticação da tecnologia, o risco de contaminação aumentou consideravelmente.

$\mathrm{Na}$ década de 50, os níveis de oxigênio de importantes rios urbanos de países ricos baixaram a patamares críticos - chegaram a cerca de $10 \%$ do volume normal. Em Londres, um barco chegou a ser usado para injetar oxigênio puro diretamente na água, uma solução cara e com resultados limitados.

Os últimos levantamentos da ONU a esse respeito são bastante eloqüentes. De acordo com ela, os 14 maiores rios europeus têm nascentes com "bom status ambiental", mas no resto de seu percurso, estão bastante degradados. Na Ásia, todos os rios que cruzam cidades estão altamente poluídos. Se o ritmo de crescimento da poluição continuar acompanhando o da população, a terra poderá perder 18 mil quilômetros quadrados de águas doces até 2050 quase nove vezes o volume total usado a cada ano em irrigação no mundo. Ainda segundo a ONU os pobres são, como é de se imaginar, os mais afetados pela poluição. Metade da população de países em desenvolvimento está exposta a mananciais poluídos. O quadro é particularmente grave na Ásia, onde os rios têm três vezes mais bactérias originárias de esgotos do que a média mundial. Além disso, os corpos d'água asiáticos apresentam taxas de enxofre até vinte vezes superiores às de países ricos.

No Brasil em torno de sessenta milhões de brasileiros não dispõem de coleta de esgoto, além disso, no norte e nordeste, quinze milhões de pessoas não têm sequer acesso à água encanada. No mundo a situação não é muito diferente, mais de um bilhão de pessoas não têm acesso à água potável e 2,7 bilhões vivem em domicílios sem saneamento básico.

As águas são poluídas, basicamente, por dois tipos de resíduos: os orgânicos, formados por cadeias de carbono ligadas a moléculas de oxigênio, hidrogênio e nitrogênio, e os inorgânicos, que têm composições diferentes.

Os resíduos orgânicos normalmente têm origem animal ou vegetal e provêm dos esgotos domésticos e de diversos processos industriais ou agropecuários. São biodegradáveis, ou seja, são destruídos naturalmente por microorganismos. Entretanto, esse processo de destruição acaba consumindo a maior parte do oxigênio dissolvido na água, o que pode comprometer a sobrevivência de organismos aquáticos. Já os resíduos inorgânicos vêm de indústrias principalmente as químicas e petroquímicas e não podem ser decompostos naturalmente.

Entre os mais comuns estão chumbo, cádmio e mercúrio. Conforme sua composição e concentração, os poluentes hídricos têm a capacidade de intoxicar e matar microorganismos, plantas e animais aquáticos, 
tornando a água imprópria para o consumo ou para o banho.

Em função de condições de escassez em quantidade e ou qualidade, a água deixou de ser um bem livre e passou a ter valor econômico. Esse fato contribuiu com a adoção de novo paradigma de gestão desse recurso ambiental, que compreende a utilização de instrumentos regulatórios e econômicos, como a cobrança pelo uso dos recursos hídricos.

A Água formada por um átomo de oxigênio e dois átomos de hidrogênio em ligação covalente, contribuição mútua na busca da estabilidade angular.

Água, fase líquida, símbolo da limpeza, da pureza e da fé.

Eis a mão do homem que através de ações ou omissões vem através dos tempos transformando a pureza das substâncias em produtos pouco desejáveis. Acompanhando o movimento tortuoso das sinuosas vias do comportamento humano balizados pelos modernos e discutíveis padrões de referência, éticos, morais e culturais.

O homem pelo homem, também capaz de ser o divisor, o meio, o separador.

\section{GÊNESIS 1, 26}

Então Deus disse: "Façamos o homem à nossa imagem e semelhança. Que ele domine os peixes do mar, as aves do céu, os animais domésticos, todas as feras e todos os répteis que rastejam sobre a terra."

\section{GÊNESIS 1, 29}

\section{E Deus disse: "Vejam! Eu entrego a} vocês todas as ervas que produzem semente e estão sobre toda a terra, e todas as árvores em que há frutos que dão semente: tudo isso será alimento para vocês.

“Obrigado Senhor, pelo húmus da terra, pela relva molhada, pelo alimento colhido, pelo amor surpreendido, pela tenra e eterna infinitude, como no primeiro entardecer".

"Perdoa-nos Senhor, pela morte do planeta, pelo afogar das esperanças, pelo não tomai e não comei, pelo conter das emoções, mesmo ao último amanhecer".

Todos nós em algum momento de nossas vidas quando desfrutando de momentos de lazer ou de introspecção já tivemos oportunidade de interiorizar pensamentos que nos remeteram à perfeição da natureza: seja a rotação dos planetas no sentido de não colisão, seja o sol a aquecer a existência do homem na terra ou estrelas a iluminar as belas noites de inverno.

Cada ser humano deste planeta certamente teria alguma particularidade em relação aos seus aspectos de senioridade, sem que houvesse repetições entre os exemplos citados.

Assim seria inimaginável crer ou acreditar que tivesse havido alguma falha na projeção do "balanço alimentar da mãe natureza"!

Naturalmente, sempre fomos sabedores dos problemas da fome no mundo. Os dados do Banco Mundial e da Organização para a Alimentação e Agricultura (FAO) indicavam números para lá de significativos.

Já no início dos anos 80, entre 700 milhões e um bilhão de pessoas viviam em absoluta pobreza ao redor do mundo. No continente Africano cerca de um para cada quatro ser humano é subnutrido. $\mathrm{Na}$ Ásia e no pacífico $28 \%$ da população passam fome. Segundo a Organização Mundial de Saúde (OMS) a fome crônica afeta mais que 1,3 bilhões de pessoas.

Quais serão as verdadeiras razões que afetam a produção de alimentos no mundo?

- A terra não possui condições para produzir alimentos suficientes?

- O número de habitantes no planeta cresce em projeção logarítmica, sendo assim não há demanda suficiente?

- No mundo a extensão de terras cultiváveis é inferior ao necessário?

Provavelmente, alguns mandatários espalhados pelo mundo sentir-se-iam bastante confortáveis na remota possibilidade de pessoas com um mínimo de informações acreditarem em tais "balelas".

Porém, mais incomodativo para aqueles cidadãos que imaginam ser possuidores de pouco mais subsídios, é tentar compreender como a economia neoclássicaonde as empresas vendem bens e serviços e com isso remuneram os fatores de produção (terra, trabalho e capital)- poderá algum dia trabalhar alinhada e equilibrada com a economia ecológica.

Esta enxerga o planeta terra como um sistema aberto à entrada de energia solar. Nessa economia, a manutenção da biodiversidade é 
tratada de forma primordial, sendo respeitadas as relações de energia versus produtos e reciclados.

Atualmente, metade da agricultura mundial é voltada para a produção de ração para animais. A carne dos animais abatidos é acessível a menos de $15 \%$ dos seres humanos. O consumo mundial de carne está restrito a poucos países, dentre estes podem ser citados, Estados Unidos, União Européia, China e Brasil que concentram o consumo global de cerca de $60 \%$ de carne bovina, mais de $70 \%$ de carne de frango, e mais de $80 \%$ de carne de porco.

Em outras palavras, significa dizer que o resto da população mundial pratica um semi-vegetarianismo consentido. Números e dados informam que para alimentar uma população de 6,5 bilhões de habitantes seria necessário mais dois planetas como a terra só para pastagens e produção de grãos /ração.

Qualquer leitor observando os dados acima tem o direito de intuir que este balanço de massa é totalmente injusto e não homogêneo com a maioria esmagadora do planeta.

Porém, os exemplos citados acima são apenas uma gota em um vasto oceano chamado "fome no planeta".

Utilizando a lógica matemática e supondo a configuração final destes números, um modelo operável, esta ferramenta indicativa comporta uma extrapolação para qualquer tipo de modelo funcional onde os algoritmos significativos serão sempre representados pelas forças políticas e econômicas, pela conveniência da distribuição de recursos em relação aos interesses de grandes empresas e oligarquias seculares.

Para ilustrar as suposições levantadas acima, um fato que chamou atenção neste início de 2008 e que diz respeito ao Brasil foi o fato da mídia mundial insistir em noticiários tendenciosos referentes aos biocombustíveis. Eleger os biocombustíveis como grande vilão da escassez de alimentos no mundo é no mínimo uma indelicadeza com a neuroquímica dos nossos sentidos.

Como observa a professora da Universidade Federal do Rio de Janeiro (UFRJ), Susana Kahn Ribeiro, o etanol obtido nos Estados Unidos tem como matriz o milho. Neste caso houve um desvio da produção alimentar para aumentar a geração de biocombustível.
Em função da redução da oferta do milho o preço dos derivados subiu, dando início um processo de reação em cadeia e culminando com o aumento do preço da ração dos animais e conseqüentemente das carnes.

Enquanto no Brasil onde o etanol é produzido através da cana de açúcar a relação custo-benefício é totalmente favorável à utilização desta matriz. Além do nosso histórico dos últimos trinta anos indicarem tanto o aumento da produção de etanol quanto o crescimento na produção de alimentos.

Entretanto, devemos observar as questões ambientais e trabalhistas que envolvem a produção de etanol em larga escala.

O Brasil é um dos poucos países no mundo onde existem condições para ampliação da produção agrícola. Aliado a esta possibilidade, além de poder ratificar o título declamado pelas gerações passadas de celeiro do mundo, deveríamos embalar o sonho da prática da agricultura sustentável.

O equilíbrio, a sustentabilidade já não é tratativa para um futuro próximo, é uma imposição de urgência. As práticas desenvolvidas na agricultura sustentável certamente produziriam as seguintes conseqüências:

- manutenção em longo prazo dos recursos naturais e da produtividade;

- mínimo de impactos negativos ao meio ambiente;

- retorno adequado aos investidores;

- otimização da produção com mínimo de insumos externos;

- satisfação das necessidades humanas de alimento e renda;

- atendimento às demandas sociais das famílias e comunidades rurais.

$\mathrm{Na}$ esperança do amanhã, sentido primordial da vida, ansiosamente espera-se que os desígnios da criação sejam cumpridos pelo homem, principalmente nos aspectos de dominação e utilização da biodiversidade.

Sejamos feito a imagem e semelhança como na origem do universo. Para tanto, prevaleça a característica que mais nos diferencia dos outros habitantes deste planeta, qual seja, o pensamento.

Que este seja aqui simbolizado pelos caminhos e letras do equilíbrio "samatva", quase sem forças, quase na escuridão, na liberdade de expressão daqueles que sonham 
Minha casa transparente

Descortino o profundo, o impenetrável Grossas gotas em queda, sob a luz dos trovões

Incessante ausência de sem tido

Faz refletir

Fumaças de inspiração

Névoas de condensação

Ausência de visão

Natureza viva, esquálida

Templo angelical

Em universo vegetal, apenas animais

Quanto a você, intruso!

Entre espelhos a observar

O olhar ao longe do amanhã

Encravado no reverso

Em busca de equilíbrio

Entre a momentânea lucidez

E a derradeira

LUZ.

\section{Bibliografia Recomendada}

- Bíblia Sagrada. Edição Pastoral, São Paulo: Paulus, 1990.

- PAPA, João Paulo II; Cruzando o Limiar da Esperança, 1 ed. Rio de Janeiro: Francisco Alves, 209pp.,1994.

- LEEF, Enrique; Saber Ambiental; Petrópolis: Vozes, 343pp., 2001.

- BOFF, Leonardo; Ecologia Grito da Terra Grito dos Pobres, São Paulo: Ática, 339pp.,2000.

- BOFF, Leonardo; Espiritualidade um Caminho de Transformação, 2ed. Rio de Janeiro: Sextante, 94pp., 2001
- TRIGUEIRO, André (coordenador); Meio Ambiente no Século 21, Rio de janeiro: Sextante, 367pp., 2003.

- www.folha.com.br; A crise dos Alimentos e

o Brasil, acesso em 10 de Maio de 2008

- BOHR, Niels; Física e Conhecimento Humano, Rio de janeiro: Contraponto, 140pp., 1995.

- BRAUN, Ricardo; Desenvolvimento ao Ponto Sustentável; Petrópolis: Vozes, 173 pp.,2001.

- RAVAGLiA, Rosana; Desenvolvimento Sustentável: Apostila Interdiciplinar em Políticas de Educação em Saúde, 2003.

- BREDARIOL, Celso; VIEIRA, Liszt; Cidadania e Política Ambiental; Rio de Janeiro: Record, 171pp., 1998.

- MARIANO, Rubem; A polêmica sobre a fome mundial e os biocombustíveis, www. google.com.br; acesso em 10 de Maio de 2008 .

- BOFF, Leonardo; Ética e Moral, Petropolis: Vozes, 125pp.,2003.

- ALIER, Joan Martinez; Da Economia Ecológica ao Ecologismo Popular; Blumenau: FURB, 402pp.,1998.

- KONDER, Leandro; Vida e Obra - Marx; São Paulo: Paz e Terra, 154pp.,1999.

- LEFF, Enrique; Epistemologia Ambiental; São Paulo: Cortez, 240pp., 2006.

\section{Informação bibliográficas:}

Conforme a NBR 6023:2002 da Associação Brasileira de Normas Técnicas (ABNT), este texto científico publicado em periódico eletrônico deve ser citado da seguinte forma:

SILVA, M. B. C.; SOARES, R. A. R.. Meio Ambiente - Na Perspectiva do Criador e da Criatura. Cadernos UniFOA, Volta Redonda, ano III, n. 6, abril. 2008. Disponível em: < http://www.unifoa. edu.br/pesquisa/caderno/edicao/06/11.pdf> 